\title{
Capital Market Theories: Market Efficiency Versus Investor Prospects
}

Kathleen Hodnett, PhD, University of the Western Cape, South Africa

Heng-Hsing Hsieh, PhD, CFA, University of the Western Cape, South Africa

\begin{abstract}
This paper reviews the development of capital market theories based on the assumption of capital market efficiency, which includes the efficient market hypothesis (EMH), modern portfolio theory $(M P T)$, the capital asset pricing model (CAPM), the implications of MPT in asset allocation decisions, criticisms regarding the market portfolio and the development of the arbitrage pricing theory (APT). An alternative school of thought proposes that investors are irrational and that their trading behaviors are driven by psychological biases such as greed and fear. Prospect theory and the role of behavioral finance that describe investment decisions in imperfect capital markets are presented to contrast the Utopian assumption of perfect market efficiency. The paper concludes with the argument of Hirshleifer (2001) that heuristics are shared by investors and asset prices may not reflect their long-term intrinsic values as indicated by efficient capital market theories.
\end{abstract}

Keywords: Capital Market Theories; Markowitz Portfolio Theory; Capital Asset Pricing Model; Arbitrage Pricing Theory; Behavioral Finance; Prospect Theory; Efficient Market Hypothesis; Separation Theorem; Roll's Critique; the Benchmark Error

\section{INTRODUCTION}

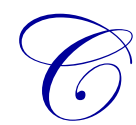

apital market theories provide the foundation for the development of financial asset pricing models. The mainstream view of capital markets adopt the perfect-world scenario where markets are perfectly efficient with regard to information in that asset prices quickly and accurately reflect new information as it arrives in the market. Under the assumption of efficient capital markets, all investors are risk-averse and completely rational in making their decisions. Theories developed based on the assumption of efficient capital markets include the efficient market hypothesis (EMH), Markowitz's portfolio theory, the separation theorem, the capital asset pricing model (CAPM) and the arbitrage pricing theory (APT). The EMH is regarded as the fundamental theory underpinning all areas of finance. Modern Portfolio Theory (MPT), pioneered by Markowitz (1952) and the separation theorem of Tobin (1958) provide solutions for risk-averse investors to allocate assets in an efficient capital market. Under the assumptions of MPT, risk-averse investors have homogeneous expectations regarding the mean, variance, and covariance of asset returns, and aim at maximizing their expected utility when making investment decisions. The concept of risk aversion stems from the expected utility theory, which describes the decision making process of investors in the presence of risk and is based on investor rationality.

As an extension to the existing framework of MPT, the capital asset pricing model (CAPM) is developed to price assets in an efficient capital market. The essence of MPT surrounds a completely diversified optimal risky portfolio called the market portfolio that all investors are assumed to hold, and the only source of risk in an investment is its sensitivity to movements in the market portfolio, since any firm-specific risk can be diversified away by holding the market portfolio. The concept of the market portfolio is criticized and a multifactor asset pricing model developed under the arbitrage pricing theory (APT) is viewed as an alternative to the CAPM in pricing assets in an efficient capital market.

An alternative school of thought, behavioral finance, built on the likelihood of investor behaviors, or investor prospects, challenges the assumptions of market efficiency, particularly investor rationality. While traditional finance make suggestions regarding the manner in which assets should be priced in efficient markets, 
behavioral finance argues that the cognitive behavior of irrational investors have pervasive impact on the pricing of assets in capital markets. Kahneman and Tversky (1979) question the tenets of the expected utility theory, and introduce prospect theory which describes investor decisions under the influences of cognitive psychologies.

\section{THE EFFICIENT MARKET HYPOTHESIS}

An efficient market is the term used to describe a market where investors cannot outperform their rivals by generating abnormal risk-adjusted returns in a consistent manner. With the intention to maximize their wealth, investors utilize information that is accessible to them as tools in trading available assets in the capital market. The historical price patterns and volume data of assets are regarded as the most basic tools available to investors in the market. Other types of information include public announcements of company performance results and inside information that is either not fully understood or accessible to average investors in markets that are not perfectly efficient. Investors who utilize historical price patterns and volume data of assets to time the market and allocate their assets are called technical analysts or technicians. For technicians to outperform the market, the movements of asset prices must follow certain trends and be predictable to some degree. In other words, the asset prices cannot follow a "random walk", which is defined by Fama (1970) as successive price changes being independent over time.

In an attempt to test whether historical price patterns of assets are repetitive and thus predictable to technicians, Kendall (1953) statistically analyzes the time-series behavior of 22 economic series over the period from 1883 to 1934 using the actuaries' indexes of industrial stock prices as the dataset. The test results reveal that stock prices are unpredictable in that the serial correlations within the selected series are weak, and there are no statistically meaningful correlations between the series. Samuelson (1965) offers mathematical proof to support the findings of Kendall (1953) based on stochastic modeling of asset prices. Samuelson (1965: 41) postulates that "in competitive markets there is a buyer for every seller. If one could be sure that a price will rise, it would have already risen". Based on the analogy of Samuelson (1965), the random walk behavior of asset prices documented in Kendall (1953) is attributable to the instantaneous incorporation of new information in asset prices via competition of market participants. For competition in the market to be regarded as a fair game, accurate information must be accessible to all interested parties instantaneously and there has to be no barriers to trade. Ideally, a perfectly efficient capital market is "a market in which firms can make production-investment decisions and investors can choose among the securities that represent ownership of firms' activities under the assumption that security prices at any time fully reflect all available information" (Fama, 1970: 383).

Fama (1965, 1970 and 1991) reviews the empirical work on the random walk of asset prices and introduces different forms of market efficiency under the efficient market hypothesis (EMH) based on the manner in which different types of information are reflected in asset prices. According to Fama (1965), the levels of market efficiency can be divided into three forms: the weak form, semi-strong form and the strong form. Each form of the EMH has the ability to rule out the possibilities of consistent outperformance by a certain group of investors who use certain type of information as the tool in their trading activities. As the market becomes more efficient, the particular "tool" that investors used to beat the market become less effective since most of the investors would have learnt the use of it and practice their trading activities accordingly. While asset prices fully reflect historical price patterns in the weak-form version of the EMH, asset prices in the semi-strong form version of the EMH reflect all publicly available information such as corporate earnings, share splits, etc. This implies that technical analysts who employ price charts and volume data in making their investment decisions cannot earn positive abnormal returns in a consistent manner in a market that is weak-form efficient. On the other hand, fundamental analysts who study macroeconomic forces and company performances cannot beat a market that is semi-strong form efficient. When a market is categorized as being strong-form efficient, company insiders do not have monopolistic access to information relevant for price formation, and hence inside information does not exist in such a market.

\section{ASSET ALLOCATION IN AN EFFICIENT CAPITAL MARKET}

"The primary role of the capital market is allocation of ownership of the economy's capital stock" (Fama, 1970: 383). Based on the assumption of market efficiency and the principle of diversification, Markowitz (1952) developed the first theory that incorporates the concept of risk in the portfolio management process. The attitude of investors towards risk in the portfolio theory of Markowitz (1952) is based on the concept of risk aversion described 
by the expected utility theory, which is expressed by the conventional utility curve illustrated in Figure 1 . Using the asset position as an indication of wealth, the positive slope of the utility function indicates that the higher the asset position, the higher the investor's utility. However, the utility function is concave, indicating that the marginal utility derived from the growth in the asset position is diminishing. This implies that investors will reject a risky venture without adequate compensation for its risk (Bodie, Kane and Marcus, 2008).

Figure 1: Risk Aversion and Marginal Utility

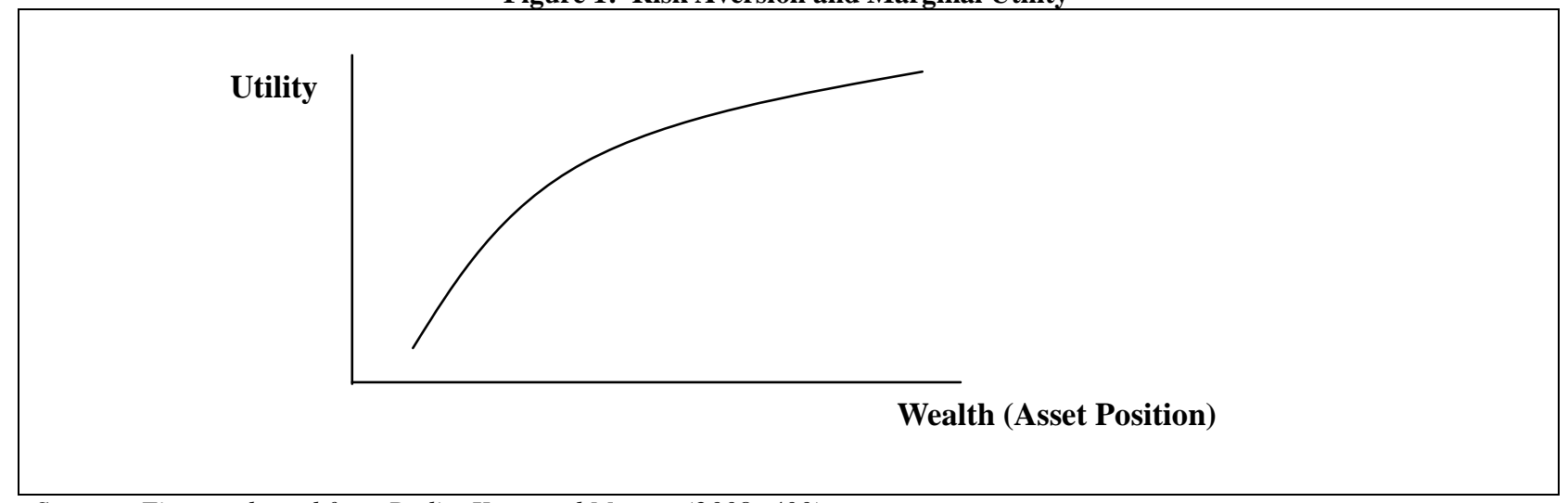

Source: Figure adapted from Bodie, Kane and Marcus (2008: 400)

Under the expected utility theory, investors make decisions between alternative investments based on the expected utility that can be achieved from the respective investments as shown in Equation 1 (Kahneman and Tversky, 1979: 263):

$$
E(U)=p_{1} u\left(x_{1}\right)+p_{2} u\left(x_{2}\right)+\ldots+p_{n} u\left(x_{n}\right)
$$

Where:

$x_{1}, x_{2} \ldots x_{\mathrm{n}} \quad$ are the possible asset positions of the investment; and

$p_{1,} p_{2} \ldots p_{n} \quad$ are the probabilities assigned to the possible asset positions of the investment.

The decision making process based on the utility function depicted by Equation 1 is rational and not subject to psychological biases since the decision relies purely on the probabilities of the various possible asset positions of an investment. Applying the concept of risk aversion to the portfolio construction process, rational investors will prefer to include assets that offer a higher expected return for a given level of risk, or a lower risk for a given level of expected return in their portfolios. Equation 2 and Equation 3 mathematically demonstrate the expected return and the variance of a portfolio that consists of two assets $i$ and $j$. The weights carried by constituents $i$ and $j$ are proportional to their relative market values:

$$
\begin{aligned}
& E\left(R_{P}\right)=\left(w_{i} \times E\left(R_{i}\right)\right)+\left(w_{j} \times E\left(R_{j}\right)\right) \\
& \sigma_{P}^{2}=\left(w_{i}^{2} \sigma_{i}^{2}\right)+\left(w_{j}^{2} \sigma_{j}^{2}\right)+\left(2 w_{i} w_{j} \sigma_{i} \sigma_{j} \rho_{i j}\right)
\end{aligned}
$$

Where:

$w_{i}$ and $w_{j} \quad$ are the weights of constituents $i$ and $j$ in portfolio $P$;

$\sigma_{i}$ and $\sigma_{j} \quad$ are the standard deviations of constituents $i$ and $j$ in portfolio $P$; and

$\rho_{i j} \quad$ is the correlation coefficient between the returns of constituents $i$ and $j$ in portfolio $P$. 
While the expected return of a portfolio is computed as the weighted average of the expected returns of its constituents, the portfolio risk measured by the standard deviation (square root of variance) of historical returns is less than the weighted average of the standard deviations of its constituents. This is because the returns of the constituents in a portfolio are likely to be less than perfectly correlated, and hence the firm-specific risk of a large portfolio is effectively diversified away. As shown in Equation 3, the lower the correlation coefficient between the returns of the constituents in the portfolio, the lower is the variance and hence the standard deviation of the portfolio. As a result, the total risk of the portfolio does not increase in the same proportion as the increase in the portfolio expected return when a new asset with higher expected return is added to the portfolio.

Incorporating the concept of diversification discussed, the Markowitz efficient frontier of risky assets is derived from efficient mean-variance optimization with the objective of maximizing the expected return of the portfolio at each level of portfolio standard deviation from the feasible set of risky assets. Figure 2 illustrates the umbrella-shaped Markowitz efficient frontier of risky assets. The assets plotted on the efficient frontier represent the mean-variance efficient risky assets attainable from the feasible set of risky assets. The risky assets plotted on the efficient frontier are preferred by risk-averse investors to other assets in the feasible set as they offer the highest attainable returns for the given levels of risk.

Figure 2: Markowitz Efficient Frontier of Risky Assets

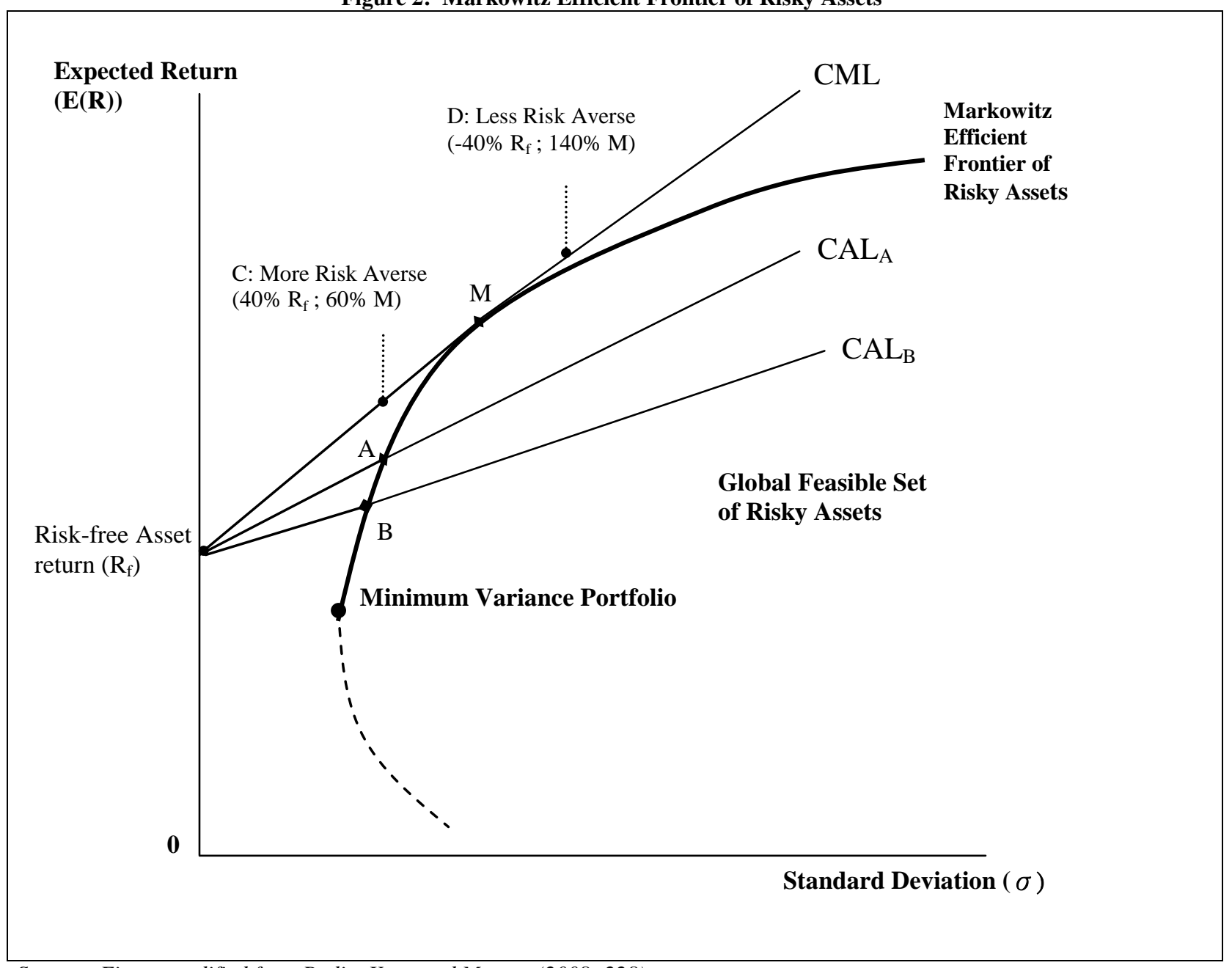

Source: Figure modified from Bodie, Kane and Marcus (2008: 228) 
The Markowitz efficient frontier is comprised of only risky assets. To manage the risk of the portfolio effectively, investors can invest a fraction of their capital in an asset that provides returns of certainty. The proxy for the risk-free asset is usually a highly liquid Treasury security with low probability of default. Consider the meanvariance efficient portfolios A and B in Figure 2. Any combination of portfolio A and the risk-free asset in an investor's portfolio can be represented by a linear capital allocation line $\left(\mathrm{CAL}_{\mathrm{A}}\right)$ drawn from the risk-free rate $\left(\mathrm{R}_{\mathrm{f}}\right)$ through A. ${ }^{1}$ Similarly, $\mathrm{CAL}_{\mathrm{B}}$ represents any combination of portfolio $\mathrm{B}$ and the risk-free asset in an investor's portfolio. $\mathrm{CAL}_{\mathrm{A}}$ dominates $\mathrm{CAL}_{\mathrm{B}}$ because combinations of portfolio $\mathrm{A}$ and the risk-free asset provide a higher expected return at any given level of risk than combinations of portfolio B and the risk-free asset. Therefore, all investors would prefer to form their portfolios using the risk-free asset with portfolio A rather than with portfolio B. In this manner, one can continue to ratchet the CAL upward until it reaches the ultimate point of tangency with the efficient frontier of risky assets at $\mathrm{M}$.

The ultimate CAL tangent to the optimal risky portfolio is termed the capital market line (CML), which offers the highest possible expected return for any given level of risk, and the lowest possible risk for any given level of expected return. Equation 4 depicts the mathematical representation of the CML, which states that the expected return on an efficient portfolio is equal to the return on the risk-free asset $\left(\mathrm{R}_{\mathrm{f}}\right)$ plus a market risk premium $\left(E\left(R_{M}\right)-R_{f}\right)$ proportional to the total risk of the portfolio $\left(\sigma_{\mathrm{p}}{ }^{2}\right)$ relative to the total risk of the market portfolio $\left(\sigma_{M}{ }^{2}\right)$ :

$E\left(R_{P}\right)=R_{f}+\sigma_{P}^{2} \times\left(\frac{E\left(R_{M}\right)-R_{f}}{\sigma_{M}^{2}}\right)$

Where:

$E\left(R_{P}\right) \quad$ is the expected return of portfolio $P$;

$E\left(R_{M}\right) \quad$ is the expected return of the market portfolio $M$;

$R_{f} \quad$ is the return on the risk-free asset;

$\sigma_{P}^{2} \quad$ is the variance of portfolio $P$; and

$\sigma_{M}^{2} \quad$ is the variance of the market portfolio $M$.

The tangency portfolio $\mathrm{M}$ is termed the market portfolio, which is regarded as the optimal risky portfolio on the Markowitz efficient frontier of risky assets. The market portfolio is also a completely diversified portfolio, which contains not only domestic stocks and bonds, but also real estate, options, art, stamps, coins, human capital, foreign stocks and bonds, etc. In addition, supply and demand ensure that all assets included in the market portfolio are in proportion to their respective market values in equilibrium (Reilly and Brown, 2003). According to the separation theorem of Tobin (1958), the identification of the market portfolio is the first step in the asset allocation process. Investors, having homogeneous expectations, would arrive at the same optimal risky portfolio.

The second task of the asset allocation process involves the determination of the split between the risk-free asset and the market portfolio (that is, choosing the best point on the CML). This task, however, depends on a particular investor's risk preference. If an investor is relatively risk-averse, he might lend some part of his portfolio at the risk-free rate (for example, $40 \%$ ) by buying some risk-free assets and investing the remainder (60\%) in the market portfolio (see point $\mathrm{C}$ in Figure 2). On the contrary, if an investor prefers more risk, he might borrow funds at the risk-free rate (for example, -40\%) and invest everything (all of his capital plus what he borrowed, that is, $140 \%$ ) in the market portfolio (see point D in Figure 2). The separation theorem serves as the guideline for rational investors with different degrees of risk aversion to allocate assets in an efficient capital market.

\footnotetext{
${ }^{1}$ A capital allocation line (CAL) is a plot of risk-return combinations available by varying portfolio allocations between a riskfree asset and a risky portfolio. The line is linear (as opposed to the curved efficient frontier) because there is no diversification benefit by including the risk-free asset in the portfolio. This is so because the variance of the risk-free asset is zero by definition, and hence there exists a zero correlation between the return on any risky asset and the risk-free rate.
} 


\section{ASSET PRICING IN AN EFFICIENT CAPITAL MARKET - THE CAPITAL ASSET PRICING MODEL}

Fuller (1981) argues that Markowitz portfolio theory and the separation theorem make no statement about how assets or portfolios should be priced in an efficient market. The capital asset pricing model (CAPM) on the other hand is a single factor linear equilibrium pricing model that assists investors in determining the equilibrium rates of return of assets in an efficient capital market. The CAPM is an extension of Markowitz portfolio theory. Sharpe (1964), Lintner (1965) and Mossin (1966) independently contribute to the development of the CAPM. The CAPM is built on the insight that unsystematic (firm-specific) risk can be diversified away, and hence investors only require to be compensated for bearing systematic (market) risk. The CAPM further states that the relevant risk (systematic risk) measure for any risky asset $i$ is its covariance with the market portfolio $\left(\sigma_{\mathrm{i}, \mathrm{M}}\right)$. By substituting $\sigma_{\mathrm{i}, \mathrm{M}}$ for $\sigma_{\mathrm{P}}^{2}$ in Equation 4, the expected return-systematic risk relationship can be expressed as follows:

$$
E\left(R_{i}\right)=R_{f}+\sigma_{i, M} \mathrm{X} \frac{\left(E\left(R_{M}\right)-R_{f}\right)}{\sigma_{M}{ }^{2}}
$$

By defining $\sigma_{i, M} / \sigma_{M}{ }^{2}$ as the beta of asset $i\left(\beta_{i}\right)$, Equation 5 can be restated as:

$$
E\left(R_{i}\right)=R_{f}+\beta_{i}\left(E\left(R_{M}\right)-R_{f}\right)
$$

Equation 6, known as the security market line (SML), assists investors in determining the "conditions for equilibrium of exchange of the assets" (Mossin, 1966: 769). Mossin (1966: 769) explains, "each individual brings to the market his present holdings of the various assets, and an exchange takes place. We want to know what the prices must be in order to satisfy demand schedules and also fulfill the condition that supply and demand be equal for all assets. To answer this question we must first derive relations describing individual demand. Second, we must incorporate these relations in a system describing general equilibrium. Finally, we want to discuss properties of this equilibrium". According to the pricing system of the SML described by Equation 6, the expected return on any asset or portfolio $i\left(\mathrm{E}\left(\mathrm{R}_{\mathrm{i}}\right)\right)$ is equal to the risk-free rate $\left(\mathrm{R}_{\mathrm{f}}\right)$ plus the market risk premium $\left(\mathrm{E}\left(\mathrm{R}_{\mathrm{m}}\right)-\mathrm{R}_{\mathrm{f}}\right)$ proportional to its systematic risk $\left(\beta_{\mathrm{i}}\right)$ when the capital market is in equilibrium. In other words, assets with higher values of beta must offer higher returns in order to compensate investors for bearing higher systematic risk.

Figure 3 graphically depicts the systematic risk-expected return relationship described by the SML. When the capital market is in equilibrium, all assets must be plotted on the SML and offer returns that are justified for their respective levels of systematic risk. An asset plotted above the SML is undervalued since it offers higher returns than what is expected based on its systematic risk exposure. On the other hand, an asset is overvalued if it is plotted below the SML since it offers lower returns than what is expected for its systematic risk exposure. Consider two assets $\mathrm{U}$ and $\mathrm{O}$ that offer differential returns with the same value of beta in Figure 3. Homogeneous investors will buy asset $\mathrm{U}$ and sell asset $\mathrm{O}$ since asset $\mathrm{U}$ offers higher returns than asset $\mathrm{O}$ with the same level of risk. The trading activities of the investors will bid up the price of asset $U$ and reduce the price of asset $O$. As a result, the return of asset $\mathrm{U}$ decreases while the return of asset $\mathrm{O}$ increases. This process brings both assets $\mathrm{U}$ and $\mathrm{O}$ to the equilibrium price indicated by the SML at point E in Figure 3. Due to the fact that the beta coefficient of the SML relates the covariance of any asset $i$ with the market portfolio $\left(\sigma_{\mathrm{i}, \mathrm{M}}\right)$ to the variance of the market portfolio $\left(\sigma_{\mathrm{M}}{ }^{2}\right)$, the market portfolio has a beta of 1.0 as shown in Figure $3 .{ }^{2}$ The standardization of systematic risk using the movements in the market return as the benchmark implies that the market risk is the single relevant measure of risk in an efficient capital market.

\footnotetext{
${ }^{2}$ The covariance of any asset with itself is its variance. Hence, the covariance of the market portfolio with itself is the variance of the market return (i.e. $\sigma_{\mathrm{M}, \mathrm{M}}=\sigma_{\mathrm{M}}^{2}$ ). Therefore, $\sigma_{\mathrm{M}, \mathrm{M}} / \sigma_{\mathrm{M}}{ }^{2}=1.0$.
} 
Figure 3: The Security Market Line (SML)

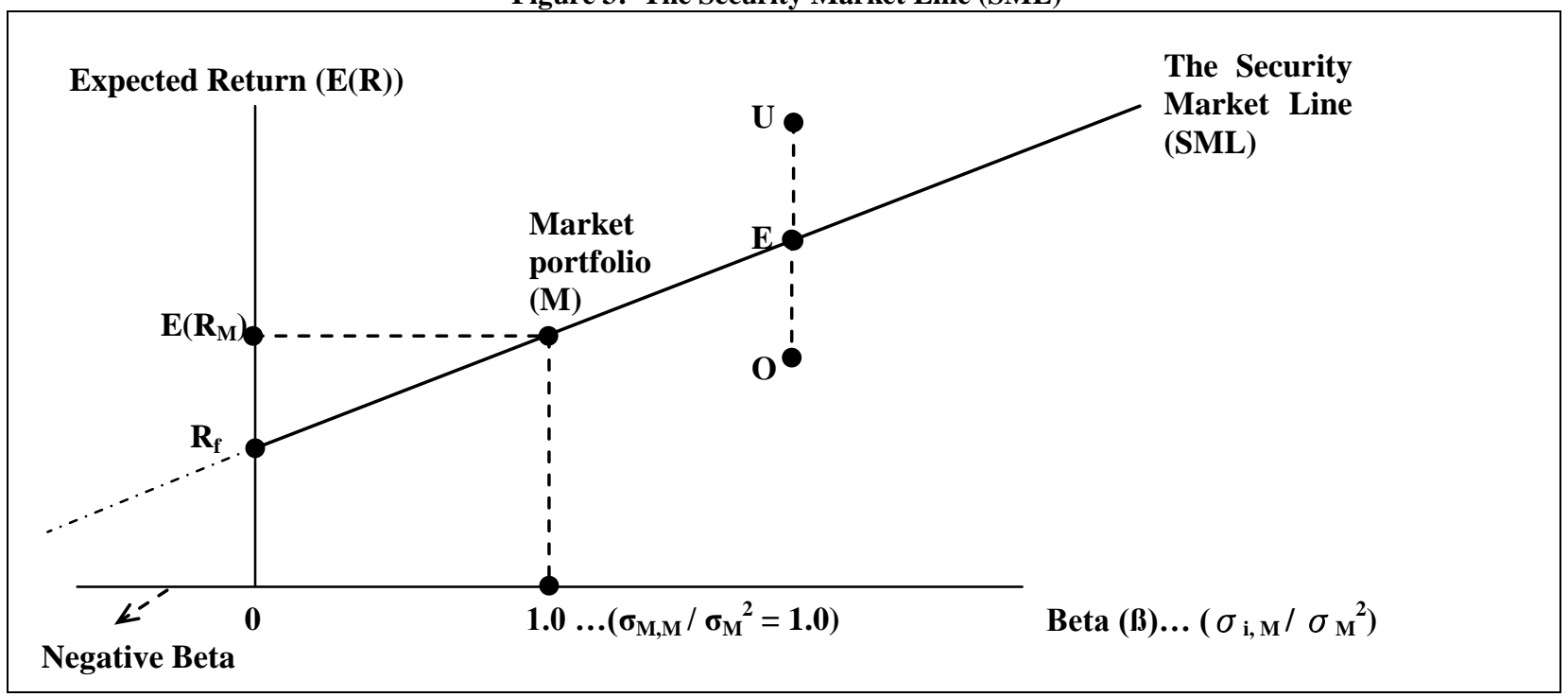

Source: Figure modified from Reilly and Brown (2003: 251)

\section{PROBLEMS WITH THE MARKET PORTFOLIO AND THE ARBITRAGE PRICING THEORY}

Although the derivation of the CAPM under MPT is intuitive in nature, Roll (1977: 129) argues that "no correct and unambiguous test of the CAPM theory has appeared in the literature, and there is practically no possibility that such a test can be accomplished in the future". This argument is based on the unobservable nature of the market portfolio since it must contain all assets in the universe in proportion to their respective market values. Thus, empirical tests of the CAPM that involves the use of general stock market indexes such as the Morgan Stanley Capital International World Index (MSCI) or the Standard and Poor's 500 Index (S\&P500) as proxies for the market portfolio are ambiguous.

\section{The Benchmark Error}

According to Roll (1978) the use of a mis-specified market proxy also suffers from the benchmark problem in pricing assets since the beta estimated and the SML derived from the inappropriate market proxies are biased. This problem is demonstrated in Figure 4 where the estimated SML yielded from the unrepresentative market proxy overvalues the high-risk portfolio $\mathrm{H}$ against the low-risk portfolio L. However, portfolio $\mathrm{L}$ is indeed undervalued while portfolio $\mathrm{H}$ is overvalued based on the evaluation of the true SML. As a result, the shaded area of Figure 4 reflects conflicting evaluations based on the estimated SML and the true SML.

\section{Derivation of the Arbitrage Pricing Model}

An alternative asset pricing model called the arbitrage pricing theory (APT) proposed by Ross (1976) partially addresses the benchmark problem of the CAPM since the APT does not require the identification of the market portfolio in its assumptions. Roll and Ross (1980) indicate that the APT recognizes that the return on the market portfolio is not the only systematic risk factor that affects the long-term average returns on individual assets or portfolios. By decomposing market risk, the APT seeks to identify major component systematic risk factors of market risk that determine the variations of asset returns in an efficient capital market. The identification of these factors help companies and investors gain an intuitive understanding of the factors' relative strength in determining asset returns. 
Figure 4: The Security Market Line (SML)

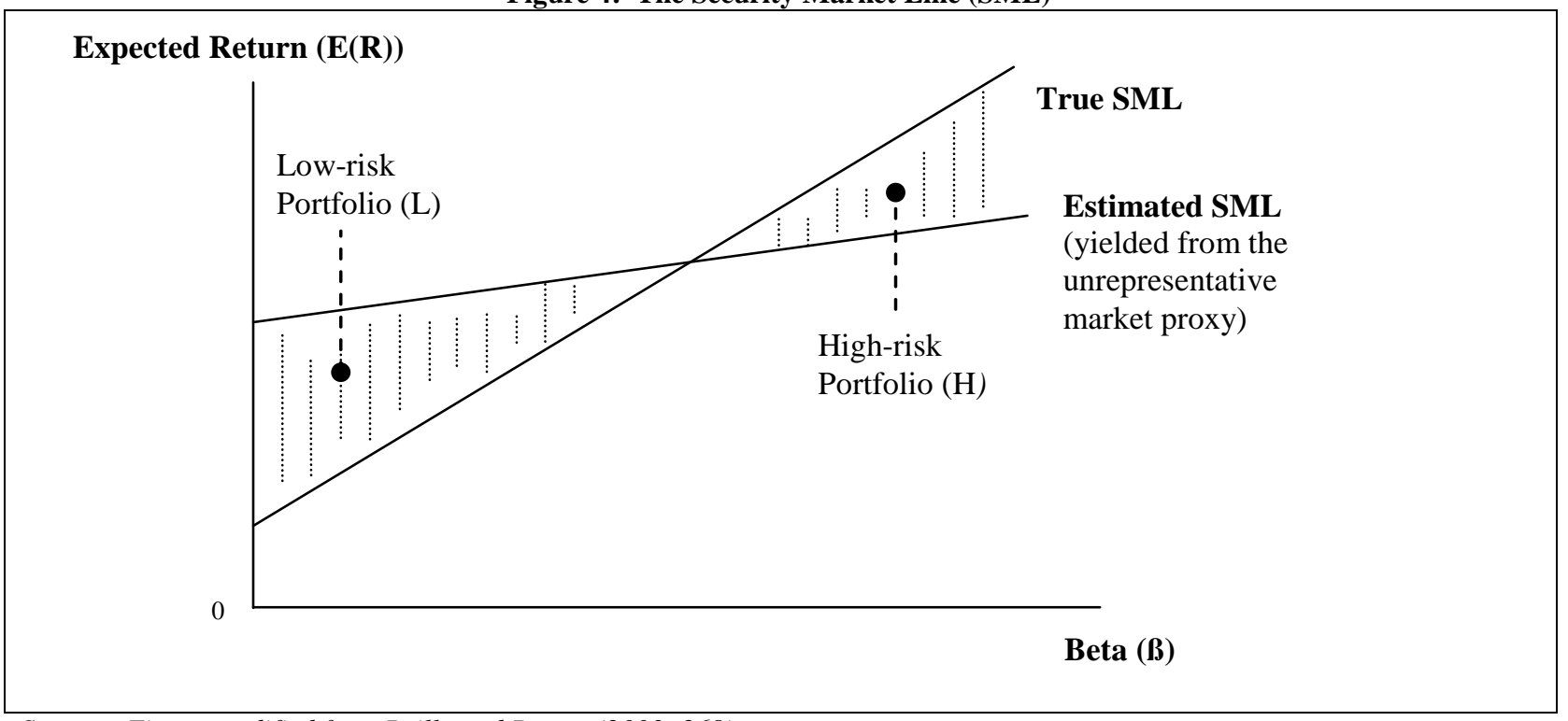

Source: Figure modified from Reilly and Brown (2003: 268)

The expected return-systematic risk relationship of the APT is depicted in Equation 7 where asset $i$ 's expected return is a linear combination of its exposures to the major systematic risks in the multifactor model:

$$
E\left(R_{i}\right)=R_{f}+b_{i 1}\left\langle E\left(R F_{1}\right)-R_{f}\right\rangle+\ldots . .+b_{i k}\left\langle E\left(R F_{k}\right)-R_{f}\right\rangle
$$

Where:

$F_{k}$

$E\left(R F_{k}\right)$

$E\left(R F_{k}\right)-R_{f}$

$b_{i, k}$

is the $k$ th systematic risk factor that is common to all assets;

is the expected return on an asset with an average sensitivity to movements in $F_{k}$;

is the expected risk premium on $F_{k}$; and

is the sensitivity of asset $i$ 's expected return to movements in the risk premium on risk factor $k$.

As a multifactor model, the APT permits companies and investors to identify various attributions of asset returns and their relative significance in determining asset returns (Modigliani and Pogue, 1988). The underlying philosophy of the APT is the law of one price. That is, two assets that bear the same level of risk cannot sell at different prices. When the law of one price is violated, there will be arbitrage opportunities allowing investors to make riskless profits with zero investment. When this occurs, an arbitrageur will sell short the asset in the highpriced market and purchase a similar asset in the low-priced market. Reconsider the undervalued asset $\mathrm{U}$ and the overvalued asset $\mathrm{O}$ in Figure 4. An arbitrageur who identifies this opportunity will sell short asset $\mathrm{O}$ and use the proceeds to finance the purchase of asset U. Such activity brings the mispriced assets to their equilibriums with no upfront investment required (Fuller, 1981). While the CAPM assumes that each investor in the investment public will take limited positions in the opportunity to bring about the capital market equilibrium, the APT proposes that any investor will take an infinite position in it.

Another major development of the APT is the recognition that the unanticipated part of the return that results from surprises is the only relevant risk of an investment. "After all, if we had already got what we had expected, there would be no risk and uncertainty" (Ross, Westerfield and Jaffe, 1990: 297). Based on this argument, the APT can be rewritten in an ex post form as shown in Equation 8 where the realized return of asset $i$ is divided into the expected portion of the return (described by Equation 7) and the unexpected portion of the return that is determined by the unanticipated movements in $k$ number of risk factors: 


$$
R_{i}=E\left(R_{i}\right)+b_{i 1}\left\langle R F_{1}-E\left(R F_{1}\right)\right\rangle+\ldots+b_{i k}\left\langle R F_{k}-E\left(R F_{k}\right)\right\rangle+\epsilon_{i}
$$

Where:

$\begin{array}{ll}R F_{k}-E\left(R F_{k}\right) & \text { is the risk premium on } F_{k} \text { that is not anticipated by the market participants; and } \\ \in_{i} & \text { is a normally distributed random error term. The correlation of } \in_{i} \text { and } \in_{j} \text { is equal to zero. }\end{array}$

Identities of the Pervasive Macroeconomic Factors

Although the APT avoids the benchmark problem by focusing on a few major systematic risk factors rather than the overall market risk, it suffers from similar criticisms since it does not indicate what the factors are. However, the possible identities of the major factors suggested by empirical research conducted internationally are generally in line with the major factors identified by Chen, Roll and Ross (1986). Chen et al (1986) conducted research on stocks listed on the New York Stock Exchange (NYSE) over the period from 1953 to 1983. The test results indicate that the unanticipated movements in: 1) the level of industrial production; 2) inflation; 3) the yield spread between low-grade bonds and government bonds and 4) the slope of the term structure of interest rates (yield curve) are significant risk factors that determine stock market returns. Chen et al (1986) further suggest that other potential factors may exist, however, they only influence asset returns through their impacts on the above-mentioned factors. Harrington (1987) indicates that these factors are also supported by the economic rationale that they exert their influences on the key determinants of the discounted cash flow (DCF) model: industrial production is the indication for future cash flows $\left(\mathrm{D}_{1}\right)$ and inflation enters to adjust the nominal growth rates $(\mathrm{g})$. The interest rates and the spread between low-grade and high-grade bonds are determinants of the discount rate for future cash flows (k).

\section{Implications of the Arbitrage Pricing Theory in Asset Allocation}

Modigliani and Pogue (1988) suggest that the distinctive advantage of the APT is that it permits investors to specifically tailor their portfolios to their tastes and circumstances by adjusting the exposure to individual risk factors. This is contrary to the CAPM since the CAPM suggests that the market portfolio is the optimal risky portfolio, and that all investors will hold part or all of their investments in the market portfolio. Roll and Ross (1984: 24) also states that "to argue that there is one best strategy for everyone - such as "buying the market" - is simply wrong". This argument implies that different investors could have portfolios with the same CAPM beta but have quite different exposures across the various risk factors. For example, blue-collar workers may be exposed to greater inflation risk than white-collar workers. Hence, Roll and Ross (1984) indicate that the major task of strategic portfolio management is to decide on the most desirable exposures to various systematic risks for their clients. The APT enhances this task by allowing portfolio managers to segment portfolio risk, and to manage portfolios actively through predicting movements in critical risk factors. For example, assume that asset A has an inflation beta of 2 and asset $\mathrm{B}$ has an inflation beta of 1 . Then, a desired inflation beta of 1.4 for a particular client's portfolio can be achieved by allocating 40 percent of the capital in $\mathrm{A}$ and 60 percent of the capital in $\mathrm{B}$ [given $(0.4 * 2)+(0.6 * 1)=$ 1.4]. Although the APT is appealing and innovative in its own merit, capital market theory remains the mainstream of traditional finance regarding portfolio management.

\section{BEHAVIORAL FINANCE}

People are rational in standard finance; they are normal in behavioral finance. Rational people care about utilitarian characteristics but not value-expressive ones, are never confused by cognitive errors, have perfect selfcontrol, are always averse to risk, and are never averse to regret. Normal people do not obediently follow that pattern (Statman, 1999: 26).

Behavioral finance is an area of study that analyzes the impact of systematic psychological biases on the decision making process of investors. The proponents of behavioral finance believe that investors are influenced by their emotions in addition to the mean, variance and covariance of asset returns in making investment choices. This 
implies that investors will not arrive at the same optimal risky portfolio as suggested by the separation theorem of Tobin (1958). Based on this analogy, it can be argued that the proposed asset allocation decision of MPT is essentially a suggestion for the "what if the market is efficient" scenario, and the studies of behavioral finance serve to provide alternative scenarios for investors in an irrational market. If the market is not as efficient as suggested by the EMH, the risk-return pricing relationship depicted by the SML of the CAPM would be biased and the portfolios constructed based on this relationship would cease to be mean-variance efficient. The major development of behavioral finance stems from prospect theory proposed by Kahneman and Tversky (1979), which presents a critique of the expected utility theory.

\section{Prospect Theory}

Prospect theory asserts that choices of investors, in the presence of risk, exhibit several pervasive effects that are inconsistent with the basic tenets of the expected utility theory. As a critique of the expected utility theory, prospect theory studies the decisions of investors in the presence of uncertainty and is based on cognitive psychology rather than investor rationality.

As discussed earlier, expected utility theory suggests that investors are risk averse when making investment decisions. In addition to the recognition of risk aversion, prospect theory introduces the concept of loss aversion, which states that investors prefer to avoid losses than to acquire gains. To demonstrate the concept of loss aversion, prospect theory suggests that investors judge the gains and losses of an investment relative to a specific reference point such as the purchase price of an asset. The utility derived from an investment can be expressed in an S-shaped value function displayed in Figure 5 (in comparison to Figure 1), where positive utility is derived from gains and negative utility is derived from losses. This value function is in line with the expected utility theory (or the marginal utility function) in that the function is concave for gains, which means that the marginal utility derived from additional gains is increased at a decreasing rate. However, prospect theory also implies diminishing marginal disutility for losses since the function becomes convex when the asset position is below the reference point. In addition, the function is steeper for losses than for gains, implying that the extent of the disutility derived from making losses is larger than the level of utility derived from an equal amount of gains.

Figure 5: Utility Function of Prospect Theory

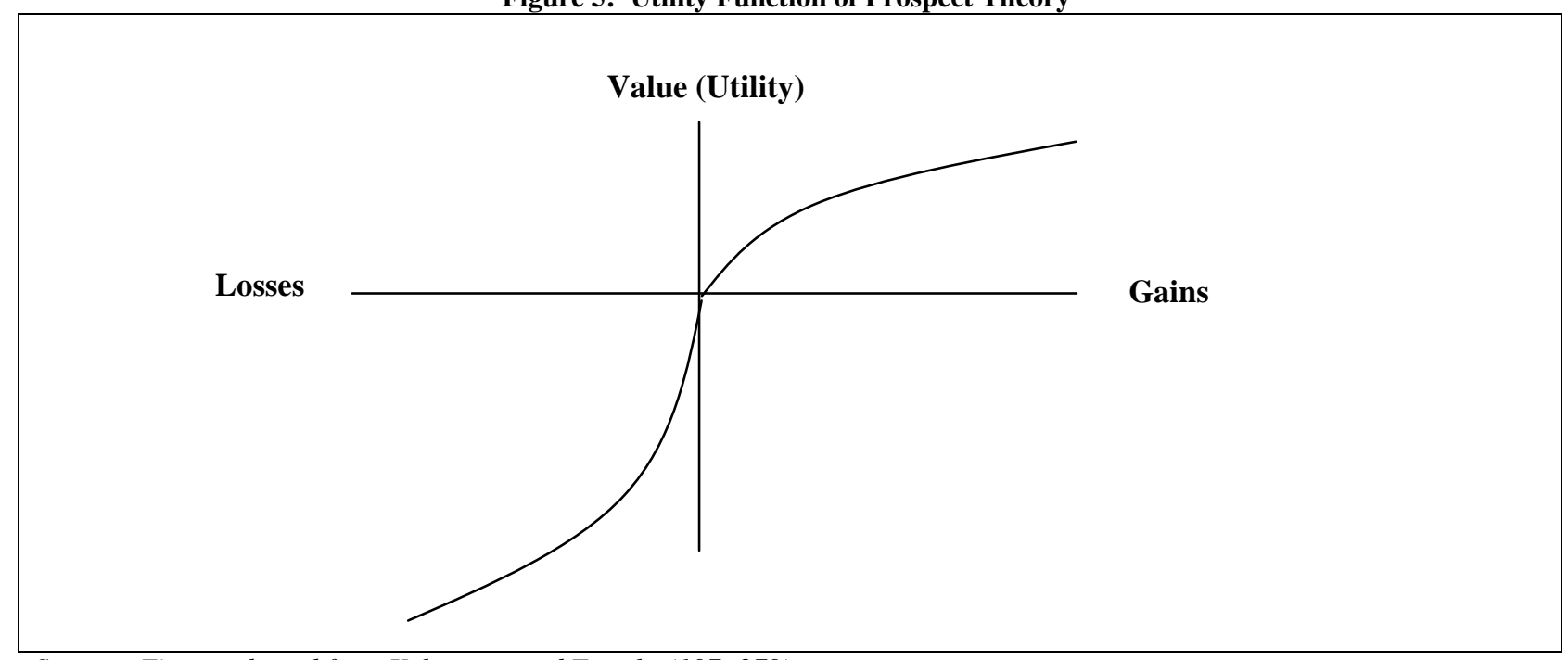

Source: Figure adapted from Kahneman and Tversky (197: 279)

Shefrin and Statman (1985) indicate that loss aversion is the consequence of seeking pride and avoiding regret by investors, which often leads them to hold losers for too long and sell winners too soon. This tendency is referred to as the disposition effect. The disposition effect is particularly strong when investors use the purchase price of their assets as the reference point to determine their gains and losses associated with their assets. 
In addition to the recognition of loss aversion, Kahneman and Tversky (1979) find that investors tend to underweight positive outcomes that are merely probable compared to positive outcomes that can be obtained with certainty. For example, people prefer to take an option that offers a guaranteed $\$ 3,000$ to an alternative that offers $80 \%$ chance of winning $\$ 4,000$ or $20 \%$ of winning nothing, while the expected value of the preferred choice is indeed $\$ 200(\$ 3,000-80 \% * \$ 4,000)$ lower than the alternative choice. This observation is termed the certainty effect, which violates the expected utility theory that weights the utilities of outcomes purely by their respective probabilities.

However, when the signs of the outcomes from the above experiments are reversed so that the potential gains in the positive domain are replaced by losses in the negative domain, Kahneman and Tversky (1979) find a reflection effect in that the preference order for the given options is reversed. More specifically, people prefer to take an option that involves $80 \%$ chance of losing $\$ 4,000$ to an option that guarantees a sure loss of $\$ 3,000$. Similar to the consequence of the choice in the positive domain, the expected loss for the preferred choice is $\$ 200$ more than the alternative choice. This observation indicates that the decisions of investors are affected by their psychological biases for ranking choices amongst positive prospects as well as negative prospects. While the certainty effect suggests that investors are over-conservative when making decisions in the positive domain, the risk-seeking of investors is exhibited in the negative domain due to the reflection effect.

Although the reflection effect suggests that investors are risk-seeking in the negative domain with high probability of loss, Kahneman and Tversky (1979) find investors to be risk-averse for small probabilities of losses. For example, people pay insurance premiums that far exceed the expected actuarial cost. The conflicting attitudes toward risk in the negative domain might contribute to the attractiveness of both insurance and gambling to investors (Kahneman and Tversky, 1979).

Another cognitive error of investors pointed out by prospect theory is that investors often segregate individual investments in their portfolios with the objective of tracking their individual gains and losses. This practice was proposed by Thaler (1985) and is referred to as mental accounting. Mental accounting neglects the importance of diversification in the portfolio concept and prevents portfolios from being mean-variance efficient.

\section{Sources of Behavioral Biases}

Hirshleifer (2001) divides the sources of behavioral biases into three major categories: heuristic simplification, self-deception and emotions. According to Hirshleifer (2001), emotions play an important role in all kinds of behavioral biases. For example, risk aversion, fear of regret and loss aversion are essentially calculated avoidance of unpleasant feelings. The importance of human emotion in decision making is also reflected in the great amount of marketing effort by companies in advertising and promoting their products.

While economists maintain that cognitive errors are unique to individuals and are offset in equilibrium, Hirshleifer (2001) argues that people often share similar heuristics. Heuristic simplification arises because cognitive constraints such as limited attention and memory forces people to simplify complicated decision making processes. Hirshleifer (2001) further suggests that "an information signal is salient if it has characteristics (e.g. differing from the background or from a past state) that are good at hooking our attention or at creating associations that facilitate recall". The psychological bias pointed out in prospective theory that involves highlighting different reference points for comparing outcomes of separate mental accounts is an act of heuristic simplification. Investors may also suffer from representativeness bias if they simplify their investment choices by allocating capital to companies with good historical results without analyzing their future prospects. Investors who use past winning stocks to represent future winning stocks fail to take into account the sustainability of the past achievements. Another mental shortcut pointed out by Nofsinger (2005) is that people often invest in companies they are familiar with, such as the companies they work for or companies in their home town. Investment choices based on familiarity leads to over-concentration of a portfolio and a lack of diversification.

Self-deception, on the other hand, leads investors to feel overconfident in their decisions due to the illusion of their knowledge. Daniel, Hirshleifer and Subrahmanyam (1998) propose a theory describing investor underreaction and overreaction in capital markets due to overconfidence and biased self-attribution of investors. The 
theory states that investors overreact to private information signals and underreact to public information signals due to their overconfidence about the precision of private information. On the other hand, the biased self-attribution of investors causes asymmetric shifts in the confidence of investors as a function of their investment outcomes. Possible consequences of biased self-attribution include stock market short-term momentum, short-term earnings drift and long-term reversals from the drift.

\section{CONCLUSION}

The efficient market hypothesis $(\mathrm{EMH})$ is based on the notion that the market is informationally efficient, meaning that asset prices reflect all relevant information as a consequence of investors competing to act on new information in order to maximize the value of their investment portfolios. While Markowitz (1952) introduces the efficient frontier of risky assets in an efficient capital market, the separation theorem of Tobin (1958) proposes the method in which investors, depending of their appetite for risk, should form their portfolios by altering the proportions of their investments between a risk-free asset and the market portfolio. Sharpe (1964), Lintner (1965) and Mossin (1966) extend the existing framework of Markowitz (1952) and Tobin (1958) to develop the capital asset pricing model (CAPM) for pricing assets in an efficient capital market. The CAPM postulates that the only relevant risk for an asset is market risk since firm-specific risk is eliminated once the asset is included in a welldiversified portfolio. Due to the critique of Roll $(1977$; 1978) that the identity of the true market portfolio is unobservable, a multifactor asset pricing model developed under the arbitrage pricing theory (APT) of Ross (1976) offers an alternative approach in the pricing of financial assets to the CAPM.

Theories and asset pricing models such as the MPT, CAPM and APT are based on the assumption of market efficiency, which provide solutions for asset allocation in markets where investors are rational in making investment decisions. The expectation theory states that investors are rational if they make their decisions purely based on the probability concept of outcomes. Behavioral finance, on the other hand, suggests that investors are irrational and often influenced by psychological biases when making decisions. The major development of behavioral finance stems from prospect theory of Kahneman and Tversky (1979), which presents several arguments against the basic tenets of the expectation theory. While the expectation theory utilizes the function of diminishing marginal utility to emphasize the risk aversion of investors, prospect theory specifically indicates that investors are risk averse for gains but exhibit diminishing marginal disutility when it comes to losses. Additionally, prospect theory introduces the concept of loss aversion, which suggests that the extent of disutility derived from losses is larger than the utility derived from an equal amount of gains. Behavioral biases lead investors to violate the assumptions of traditional finance. Instead of making investment decisions based on the mean, variance and covariance of asset returns, behavioral finance suggests that investors base their decisions on heuristics. The argument of Hirshleifer (2001) that heuristics are shared by investors suggests that assets prices may not reflect their long-term intrinsic values as indicated by efficient capital market theories.

\section{ACKNOWLEDGEMENT}

This work is supported by the National Research Foundation of South Africa. We wish to thank the research office of the University of the Western Cape for their support.

\section{AUTHOR INFORMATION}

Dr. Kathleen Hodnett is currently a Research Fellow (funded by the National Research Foundation (NRF) of South Africa) and a Senior Lecturer in the School of Business and Finance at the University of the Western Cape, South Africa. She is a member of the International Institute of Forecasters (IIF) and an associate of the South African Institute of Financial Markets (SAIFM).

Dr. Heng-Hsing Hsieh, CFA is the Head of Finance in the School of Business and Finance at the University of the Western Cape, South Africa. He is a CFA charterholder and a member of the South African Institute of Financial Markets (SAIFM). E-mail: ahsieh@uwc.ac.za. Corresponding Author 


\section{REFERENCES}

1. $\quad$ Bodie Z, Kane A and Marcus A J (2008), Investments. 7th Edition, McGraw Hill

2. Chen N, Roll R and Ross S A (1986), "Economic Forces and Stock Market", Journal of Business, vol 59, no 3, 389-403

3. Daniel K, Hirshleifer D and Subrahmanyam A (1998), "Investor Psychology and Security Market Underand Overreactions", Journal of Finance, vol 53, no 6, 1839-1885

4. Fama E F (1965), "The Behavior of Stock Market Prices”, Journal of Business, no 38, 34-105

5. Fama E F (1970), "Efficient Capital Markets: A Review of Theory and Empirical Work", Journal of Finance, no 25, 383-417

6. $\quad$ Fama E F (1991), "Efficient Capital Markets: II”, Journal of Finance, vol 46, no 5, 1575-1617

7. Kahneman D and Tversky A (1979), “An Analysis of Decision Under Risk”, Econometrica, vol 47, no 2, 263-291

8. Kendall M and Hill A B (1953), "The Analysis of Economic Time Series - Part I: Prices", Journal of the Royal Statistical Society, vol 116, no 1, 11-34

9. Fuller R J (1981), "Capital Asset Pricing Theories: Evolution and New Frontiers", Financial Analysts Research Foundation

10. Hirshleifer (2001), "Investor Psychology and Asset Pricing", Journal of Finance, vol 56, no 4, 1533-1597.

11. Lintner J (1965), "The Valuation of Risky Assets and the Selection of Risky Investments in Stock Portfolios and Capital Budgets", Review of Economics and Statistics, vol 47, no 1, 13-37

12. Markowitz H M (1952), "Portfolio Selection", Journal of Finance, vol 7, no 1, 77-91

13. Markowitz H M (1959), Portfolio Selection: Efficient Diversification of Investments, John Wiley \& Sons, New York

14. Markowitz H M (2005), "Market Efficiency: A Theoretical Distinction and So What?", Financial Analysts Journal, vol 61, no 5, 17-30

15. Modigliani F and Pogue G (1988), "Risk, Return and CAPM: Concepts and Evidence", The Financial Analyst's Handbook, 2nd Edition, edited by Levine S, Dow Jones Irwin, Homewood

16. Mossin J (1966), "Equilibrium in a Capital Asset Market”, Econometrica, vol 34, no 4, 768-783

17. Nofsinger J R (2005), The Psychology of Investing, 3rd Edition, Prentice Hall

18. Reilly F K and Brown K C (2003), Investment Analysis and Portfolio Management, 7th Edition, Thomson Learning

19. Roll R (1977), “A Critique of the Asset Pricing Theory's Tests Part I: On Past and Potential Testability of the Theory", Journal of Financial Economics, vol 14, no 2, 129-176

20. Roll R (1978), “Ambiguity When Performance is Measured by the Security Market Line”, Journal of Finance, vol 33, no 4, 1051-1069

21. Roll R and Ross S A (1980), “An Empirical Investigation of the Arbitrage Pricing Theory”, Journal of Finance, vol 35, no 5, 121-130

22. Roll R and Ross S A (1984), "The Arbitrage Pricing Theory Approach to Strategic Portfolio Planning”, Financial Analysts Journal, vol 40, no 1, 14-26

23. Ross S A (1976), "The Arbitrage Theory of Capital Asset Pricing", Journal of Economic Theory, vol 13, no 2, 341-360

24. Ross S A, Westerfield R W and Jaffe J F (1990), Corporate Finance, International Edition, Richard D. Irwin

25. Samuelson P (Spring 1965), "Proof That Properly Anticipated Prices Fluctuate Randomly", Industrial Management Review, vol 6, no 2, 41-49

26. Sharpe W F (1964), "Capital Asset Prices: A Theory of Market Equilibrium Under Conditions of Risk", Journal of Finance, vol 19, no 3, 425-442

27. Shefrin H and Statman M (1985), "The Disposition to Sell Winners Too Early and Ride Losers too Long: Theory and Evidence", Journal of Finance, vol 40, no 3, 777-782

28. Statman M (1999), "Behavioral Finance: Past Battles and Future Engagements", Financial Analysts Journal, vol 55, no 6, 18-27

29. Thaler R (1985), "Mental Accounting and Consumer Choice”, Marketing Science, no 4, 199-214

30. Tobin J (February 1958), "Liquidity preference as behavior toward risk", The Review of Economic Studies, no $25,65-86$ 
NOTES 